\title{
Primeiro registro da cochonilha Pendularia paraguariensis Granara de Willink, 1999 (Hemiptera: Coccidae) no Brasil
}

\author{
First record of Pendularia paraguariensis Granara de Willink, 1999 \\ (Hemiptera: Coccidae) in Brazil.
}

\author{
Adriano Luiz Kussler ${ }^{1}$ Sandra Mara Sabedot ${ }^{2}$ Flávio Roberto Mello Garcia $^{3}$ \\ Ana Lúcia Benta Gonzales Peronti ${ }^{4}$
}

\begin{abstract}
Pendularia paraguariensis Granara de WillinK, RESUMO 1999 (Hemiptera: Coccidae) foi registrada atacando plantas de erva-mate, pela primeira vez no Brasil, no município de Chapecó $\left(27^{\circ} 05^{\prime} 47^{\prime \prime} S, 52^{\circ} 37^{\prime} 06^{\prime \prime} W\right), S C$ de setembro de 2002 a janeiro de 2003, mas outros 32 ervais não apresentaram a ocorrência desse inseto. Esta cochonilha pode causar danos como a degeneração dos ramos primários devido a constante sucção de seiva. O contorno do corpo é oval arredondado $(2,68 \mathrm{~mm} \times 2,60 \mathrm{~mm})$ com antenas curtas e robustas com sete segmentos. Esta espécie é caracterizada pela presença e distribuição de poros preoperculares e setas hipopigiais.
\end{abstract}

Palavras-chave: erva-mate, cochonilhas, Ilex paraguariensis.

\section{ABSTRACT}

The presence of Pendularia paraguariensis Granara de WillinK, 1999 (Hemiptera: Coccidae) was reported for the first time in Brazil in the town of Chapeco, Santa Catarina State $\left(27^{\circ} 05^{\prime} 47^{\prime \prime} S\right.$, 52 $\left.37^{\prime} 06^{\prime \prime} W\right)$, attacking Paraguay tea plants (Ilex paraguariensis), from September 2002 to January 2003. Other 32 Paraguay tea plantations were inspected and there was not occurrence of this insect. This cochineal can cause degeneration of the branches where they are due to the constant suction of the sap. The contour of the body is rounded oval $(2.68 \mathrm{~mm} \times 2.60 \mathrm{~mm})$ and it has short and robust antennas with seven segments. This species is characterized by the presence and distribution of preoperculary pores and hypopygial arrows.

Key words: Paraguay tea, cochineal, Ilex paraguariensis.
A erva-mate (Ilex paraguariensis $\mathrm{St}$. Hil.) compõe um dos sistemas agroflorestais mais antigos e característicos da Região Sul do Brasil. Essa planta ocorre na região subtropical da América do Sul sendo nativa do Paraguai oriental, Brasil meridional e Argentina. Outras espécies do gênero Ilex podem ser encontradas da Bahia ao Rio Grande do Sul (HOPPE et al., 1996).

A cultura da erva-mate pode ser atacada por 16 espécies de cochonilhas de três famílias: Coccidae - Ceroplastidia grandis (Hempel, 1900), Ceroplastes hempeli Lizer 1918, Coccus hesperidum (Linnaeus, 1758), Plantinglisia noacki Cokerell, 1899, Pulvinaria convexa Hempel, 1916, Pulvinaria flavescens Brethes in Massini \& Brethes, 1918, Pulvinaria paranaensis Hempel, 1928, Saissetia oleae (Olivier, 1791), Saissetia vellozoi Vernalha, 1957; Diaspididae - Acutaspis scutiformis (Cockerell, 1893), Chrysomphalus aonidum (Linnaeus, 1758), Melanaspis paulista (Hempel, 1900), Parlatoreopsis argentata (Hempel, 1912), Pinnaspis aspidistrae (Signoret, 1869), Peudoparlatoria sp.; Pseudococcidae - Pseudococcus sp., sendo a espécie de maior ocorrência e importância econômica $\boldsymbol{C}$. grandis, cujos indivíduos podem cobrir, totalmente, os ramos dessa planta (AZEVEDO \& CORSEUIL, 1996).

\footnotetext{
${ }^{1}$ Acadêmico de Ciências Biológicas da Universidade Comunitária Regional de Chapecó.

${ }^{2}$ Biólogo da Universidade Comunitária Regional de Chapecó.

${ }^{3}$ Biólogo, Professor Dr., Universidade Comunitária Regional de Chapecó, Centro de Ciências Agro-ambientais e de Alimentos, Laboratório de Entomologia, Caixa Postal 747, 89809-000, Chapecó, SC. E-mail: flaviog@ unochapeco.rct-sc.br.Autor para correpondência ${ }^{4}$ Biólogo, Doutorando em Ecologia e Recursos Naturais pela Universidade Federal de São Carlos.
} 
Os danos diretos às plantas de $\boldsymbol{I}$. paraguariensis por cochonilhas devem-se à sucção de seiva, o que, dependendo do nível de infestação, pode debilitar ou tornar as plantas mais susceptíveis a outros agentes patogênicos. Além disso, os prejuízos indiretos por cochonilhas, incluem a liberação do excesso de seiva consumida como uma substância açucarada depositada sobre as folhas abaixo de colônias desses insetos. Este substrato permite o desenvolvimento de fungos de coloração negra do gênero Capnodium, prejudicando a capacidade fotossintética da planta, além de atrair formigas que contribuem para a disseminação desse fungo que protegem as cochonilhas contra inimigos naturais (PENTEADO, 1995).

O ataque das cochonilhas de cera, é geralmente localizado na planta de erva-mate podendo apresentar grandes infestações com prejuízos sérios. No entanto, seus ataques tem sido generalizados, principalmente em áreas com baixa presença de inimigos naturais (IEDE \& MACHADO, 1989).

Pendularia paraguariensis Granara de Willink, 1999 foi constatada na área urbana de Chapecó, SC, pela primeira vez no Brasil, atacando plantas de erva-mate com sete anos de idade. Esta espécie foi recentemente descrita por Granara de Willink, 1999 na Província de Misiones, Argentina, sendo até o momento seu único registro de ocorrência. Esse inseto pode ser identificado pelo contorno do corpo oval arredondado $(2,68 \mathrm{~mm}$ x $2,60 \mathrm{~mm}$ ), antenas curtas e robustas com sete segmentos com longitude entre as antenas de $343 \mu$, pernas bem desenvolvidas com esclerotizações tíbio-tarsais e articulações livres, apresentando coxa com $205 \mu$, trocanter mais fêmur $333 \mu$, tíbia $225 \mu$, tarso $137 \mu$ e unha $49 \mu$,. É caracterizada também pela distribuição de poros preoperculares e por setas hipopigiais (GRANARA DE WILLINK, 1999).

Foram coletadas de setembro de 2002 a janeiro de 2003, 2.197 espécimes adultos amostrados. Os insetos foram coletados ao acaso manualmente nos ramos primários da planta e após acondicionados em cápsulas gelatinosas incolores $\left(n^{\circ} 0\right)$, mantidas no Laboratório de Entomologia da Unochapecó $\left(25 \pm 3^{\circ} \mathrm{C}\right.$, $70 \pm 10 \%$, fotofase de $12 \mathrm{~h}$ ). A identificação dos insetos foi realizada pela Bióloga Ana Lúcia B. G. Peronti, doutouranda em Ecologia pela Universidade Federal de São Carlos. Constatou-se que as posturas de $\boldsymbol{P}$. paraguariensis eram efetuadas nos ramos secundários da planta. As ninfas recém eclodidas desse inseto dispersamse para ramos mais delgados e definham os mesmos com danos diretos e indiretos semelhantes aos de outras cochonilhas.

Constatou-se também, que $\boldsymbol{P}$. paraguariensis começa a suplantar a população de $\boldsymbol{C}$. grandis, considerada a cochonilha mais importante para a cultura da erva-mate, a partir do mês de novembro (Tabela 1).

P. paraguariensis pode estar, ainda, em áreas limitadas, pois outros 32 ervais de oito municípios catarinenses, sendo cinco em Chapecó, dois em Cordilheira Alta (265' $\left.15^{\circ} \mathrm{S}, 52^{\circ} 33^{\prime} 45^{\prime \prime} \mathrm{W}\right)$, cinco em Faxinal dos Guedes (26 $\left.51^{\circ} 10^{\prime \prime} \mathrm{S}, 52^{\circ} 15^{\prime} 37^{\prime \prime} \mathrm{W}\right)$, cinco em Irani $\left(27^{\circ} 03^{\prime} 45^{\prime \prime} \mathrm{S}, 51^{\circ} 56^{\prime} 15^{\prime \prime} \mathrm{W}\right)$, cinco em Ponte Serrada $\left(26^{\circ} 52^{\prime} 18^{\prime \prime S}, 52^{\circ} 00^{\prime} 57^{\prime \prime W}\right)$, três em Vargeão $\left(26^{\circ} 48^{\prime} 45^{\prime \prime S}, 52^{\circ} 11^{\prime} 15^{\prime \prime} \mathrm{W}\right)$, quatro em Xaxim $\left(29^{\circ} 0702^{\prime \prime} \mathrm{S}, 52^{\circ} 15^{\prime} 18^{\prime \prime} \mathrm{W}\right)$ e três em Xanxerê $\left(26^{\circ} 52^{\prime} 37^{\prime \prime S}, 52^{\circ} 25^{\prime} 15^{\prime \prime W}\right)$, não apresentaram a ocorrência dessa cochonilha.

A presença de $\boldsymbol{P}$. paraguariensis em apenas um erval dos 33 observados indica que essa espécie pode ter sido, recentemente, introduzida no estado de Santa Catarina. Isto pode justificar programas de erradicação dessa praga nesse estado.

Tabela 1 - Número de indivíduos e frequência de Pendularia paraguariensis e de Ceroplastida grandis em erval (Ilex paraguariensis St. Hil.) no município de Chapecó, Santa Catarina, de setembro de 2002 a janeiro de 2003.

\begin{tabular}{lcccc}
\hline Meses & \multicolumn{2}{c}{ Ceroplastida grandis } & \multicolumn{2}{c}{ Pendularia paraguariensis } \\
\cline { 2 - 5 } & $\begin{array}{l}\mathrm{N}^{\mathrm{o}} \text { insetos } \\
\text { coletados }\end{array}$ & Frequência & $\begin{array}{c}\mathrm{N}^{\mathrm{o}} \text { insetos } \\
\text { coletados }\end{array}$ & Frequência \\
\hline setembro & 432 & 72,5 & 164 & 27,5 \\
outubro & 567 & 67,3 & 276 & 32,7 \\
novembro & 482 & 26,3 & 1348 & 73,7 \\
dezembro & 124 & 27,0 & 336 & 73,0 \\
janeiro & 16 & 18,0 & 73 & 82,0 \\
\hline
\end{tabular}




\section{REFERÊNCIASBIBLIOGRÁFICAS}

AZEVEDO, E.C.G.; CORSEUIL, E. Insetos ocorrentes em ervamate. In: PREFEITURA MUNICIPAL DE VENÂNCIO AIRES. Erva-mate: diagnóstico e perspectivas de desenvolvimento. Venâncio Aires : Prefeitura Municipal, 1996. p.35-45

GRANARA DE WILLINK, M.C. Las cochinilhas blandas de la República Argentina (Homoptera:Coccoidea:Coccidae). Contributions on Entomology International, v.3, n.1, p.1-183, 1999.

HOPPE, M.; KARNOPP, E.; MEDRADO, M.J. Ervamate: diagnóstico e perspectivas de desenvolvimento.
In: PREFEITURA MUNICIPAL DE VENÂNCIO AIRES. Erva-mate: diagnóstico e perspectivas de desenvolvimento. Venâncio Aires : Prefeitura Municipal, 1996. p.7-22.

IEDE, E.T., MACHADO, D.C. Pragas da erva-mate (Ilex paraguariensis St. Hil.) e seu controle. Colombo: EMBRAPA / CNPF, 1989. 60p. (Boletim de Pesquisa Florestal).

PENTEADO, S.R.C. Principais pragas da erva-mate e medidas alternativas para o seu controle. In: WINGE, M. et al. Ervamate: biologia e cultura no Cone Sul. Porto Alegre: UFRGS, 1995. p.109-120. 